\title{
Survival of infants with unoperated myeloceles
}

\author{
M F ROBARDS， G G THOMAS， L ROSENBLOOM
}

British Medical fournal, 1975, 4, 12-13

\section{Summary}

Of the infants with spina bifida referred to a neonatal surgical unit over three years and denied early closure of the myelocele, a significant proportion survived long enough for procedures to drain hydrocephalus to be needed. The key decision in the management of this condition is not whether myeloceles should be closed but whether hydrocephalus should be treated.

\section{Introduction}

Recently the concept of selection of babies with spina bifida for early closure of the defect has become widely accepted. While the initial rationale for early closure was to preserve residual function of the legs in cases of incomplete paraplegia, for some time many centres offered early closure of the myelocele to all babies with spina bifida. Currently, however, and largely following the guidance of Lorber,' selection for early closure is now usually made not only on the basis of whether paraplegia is complete or incomplete but also on additional criteria, with the ultimate aim of selecting out a surviving group who have been operated on from a non-operated group who will die.

Babies born with spina bifida before the introduction of the Holter valve in 1958, however, did not invariably die, and with various treatments $40 \%$ survived 18 months. ${ }^{2}$ Other reviews of babies with spina bifida denied early closure of the back show a survival rate of $10-24 \%$ at 12 months. ${ }^{3-7}$ All authorities agree that the maximum mortality is within the first three months. More recently Lorber ${ }^{8}$ has shown that babies denied operative closure and active management on the basis of certain selection criteria die within nine months. These results have prompted an analysis of both the criteria used to deny patients with spina bifida early back closure and the fate of such children referred to this centre over three years.

\section{Experience in 1972}

Seventy-six new cases of spina bifida were referred in 1972, and four were denied early closure. The policy operating then was that any baby fit for general anaesthesia would be subject to immediate closure of the back. The four unfit babies all died before the age of one month.

\section{Experience in 1973}

From the beginning of 1973 there has been a more stringent policy in this unit. Seventy-eight babies were referred in $1973,26\left(33^{\prime \prime}{ }_{10}\right)$ of whom were not subjected to early closure.

Criteria for early closure were the presence of useful preservable movement in the legs (movement in addition to hip flexion) and a relatively low lesion, usually with no kyphosis. Hydrocephalus or

\footnotetext{
Department of Neonatal Surgery and Department of Neurology and Developmental Medicine, Alder Hey Children's Hospital, Liverpool 12

M F ROBARDS, MB, MRCP, senior paediatric registrar

G G THOMAS, FRCS, DCH, senior surgical registrar

L ROSENBLOOM, MRCP, DCH, consultant paediatrician
}

defective sphincters, or both, without complete paraplegia did not contraindicate early closure. Generally poor medical condition was a relative contraindication for closure.

We expected that babies with a constellation of relative contraindications would not survive longer than nine months without early closure, but this proved not to be the case. Of the 26 babies not offered early closure in 197318 died and eight survived at least a year. One died at 13 months. Those surviving at one year were compared with the non-survivors group. There were no sex differences between the groups. Two babies who arrived in poor general condition, as judged by skin colour, muscle tone, and respiration, both died. Half the infants in each group had had a complicated delivery or were asphyxiated at birth.

Neurological criteria showed that hydrocephalus was present at birth in most survivors $\left(88^{\circ}{ }_{0}\right)$ and non-survivors $\left(94^{\circ}{ }_{0}\right)$ and later developed in all babies. Over half the survivors and non-survivors had kyphosis $\left(63^{\circ}\right.$, and $67^{\circ}$, respectively), and the majority of both groups had thoracolumbar lesions $\left(88^{\circ}{ }_{1}\right.$ and $72^{\circ}{ }_{0}$ respectively). The size of the lesion did not differ significantly between the two groups. All except one baby, who died, had defective sphincters. All babies had complete paraplegia except two who survived. One of these had severe hydrocephalus with squint, spastic arms, and a large high lesion with hip flexion in only one leg. The other had a large high lesion, hydrocephalus, kyphosis, defective sphincters, talipes, and only hip flexion in the legs. There were no babies with other major congenital abnormalities. No account was taken of lacunar skull deformities, which have recently been used in assessment criteria. ${ }^{9}$ Thus none of these criteria differentiated survivors from non-survivors.

Of the 18 infants who died before the age of 1 year 15 had no Holter valve system (valve) inserted, while three did have valves inserted. Seven of the 8 who were still surviving at 12 months had valves, the remaining child dying at 13 months with severe hydrocephalus.

As in other series, the maximum mortality was early, with eight deaths in the first two weeks. Most of these deaths followed delivery complicated by instrumentation or birth asphyxia; possibly these early deaths were secondary to a more severe hydrocephalus that gave rise to a complicated delivery rather than the delivery giving rise primarily to brain damage and early death.

Of the seven survivors who had valves, two had them inserted at one month, three at two months, one at four months, and one at eight months. All of these babies were in good general condition when the valves were inserted. In three the back had already closed spontaneously and in two the back closed shortly after insertion of the valve. One myelocele was subject to secondary closure.

\section{Experience in 1974}

Fifty-three babies were referred in 1974, and $17(32 \%)$ were not subject to early closure of the back. Thus in 1973 and 1974 similar proportions of early closures were performed, but in 1974 the number of referrals had decreased. A possible explanation for this fall in the number of referrals is that referring paediatricians were selecting more carefully which babies they referred, and recent personal communications support this. There has also been a fall in birth rate in the region.

\section{Discussion}

There is considerable ambiguity and confusion over the indications for early closure of the myelocele in infants with spina bifida. Certainly, if primary closure is to be performed it is generally accepted that it must not be delayed beyond 48 hours, since the rate of infection complicating surgery then becomes very high.

When particular criteria are used to decide whether primary closure should be offered these can operate in two ways; either to define a group of babies to be excluded from early closure or to define a group in whom early closure is indicated. Exclusion 
criteria can be used to deny early closure to babies who will probably die within the first few weeks or who would have a quality of life so poor as not to merit survival. This second group is larger than the first and its selection may well involve the doctor in a commitment to actively or passively limit the infants' survival.

Our experience in 1972 shows that it is possible to predict a few of the babies who will succumb quickly, and, taken with still births, this fraction of about a fifth of all infants born with myeloceles presents few ethical problems. Our policy did mean, however, that many severely affected babies survived early closure to live with extreme handicaps. Analysis of the 1973 figures shows that when a larger group is excluded from early closure of myelocele it is not possible to predict accurately which babies will die in the first few months. Of our patients denied early closure of the myelocele $30^{\circ}$ " survived at least one year, and all except one had valves inserted. Some of these babies seem to be intellectually normal, but we do not yet have enough information about them to make predictions of their quality of life, though, certainly, their physical handicap will be severe.

In the light of these figures the explicit point needs to be made that early closure of a myelocele is not a life-saving procedure and that denial of early closure is not synonymous with early death. Rather than myelocele closure being the key to potential survival it is the drainage of hydrocephalus that is the critical procedure determining survival. Our figures, which show that no baby denied both early closure and insertion of a valve survived more than 13 months, and those of Lorber, ${ }^{*}$ which show that no baby denied both procedures survived longer than nine months, support this concept. Indeed, deaths after the first few months in babies with unoperated myeloceles are usually directly or indirectly a consequence of hydrocephalus.

Hence the medical and ethical debates on the early management of infants with spina bifida should centre on the indications for treating hydrocephalus rather than the pros and cons of early myelocele closure. A possible advantage of such a shift of emphasis is that no longer would decisions made at birth apply for the rest of an infant's life. Instead, decisions on management could be reviewed at regular intervals as determined by the patient's individual condition, as is general to medical practice.

In this unit every baby referred is assessed by the surgical team and a member of the paediatric neurological team. We have evolved the practice of recommending for early closure of the myelocele those infants with useful preservable leg movements who are in good general condition. Other babies may be subjected to early closure if there is overriding parental pressure for this despite medical advice. The pathways of both groups of infants (operated and unoperated) then run in parallel. Both groups are followed up and have whatever medical or surgical management (including insertion of a valve) their condition indicates. Thus babies denied early closure who survive the first few weeks and are in good general condition are considered for insertion of a valve and other procedures to improve their quality of life if their general condition warrants this. By the same token, babies who initially underwent early closure who later develop complications leading to severe irreversible handicap may be denied further desperate procedures.

Children with other forms of physically and mentally handicapping conditions are progressively assessed and managed by most doctors in this country in this way and there is no reason for managing babies with myeloceles in a totally different manner.

\section{References}

'Lorber, J, Archives of Disease in Childhood, 1972, 47, 854.

2 Laurence, K M, Developmental Medicine and Child Neurology, 1966, suppl $11, \mathrm{p} 10$

${ }^{3}$ Laurence, K M, and Tew, B J, Archives of Disease in Childhood, 1971, 46, 127.

${ }^{4}$ Knox, E G, Development Medicine and Child Neurology, 1967, suppl 13, p 14.

Smith, G K, and Smith, E D, British Medical fournal, 1973, 4, 189.

" Stark, G D, and Drummond, M, Archives of Disease in Childhood, 1973, $48,676$.

Sharrard, W J W, et al, Archives of Disease in Childhood, 1963, 38, 18.

" Lorber, J, British Medical fournal, 1973, 4, 201.

"Stein, C S, Schut. L, and Ames, M D, Pediatrics, 1974, 54, 553.

\title{
Transport of newborn infants for intensive care
}

\author{
A M BLAKE， N McINTOSH， E O R REYNOLDS， D ST ANDREW
}

British Medical fournal, 1975, 4, 13-17

\begin{abstract}
Summary
During the three years 1972-4 222 newborn infants were transported to this hospital for intensive care. They were collected by trained staff using a specially modified transport incubator with an in-built mechanical ventilator and facilities for monitoring body temperature, heart rate, and inspired oxygen concentration. Two of the infants came from home and the rest from 41 hospitals from half a mile $(0.8 \mathrm{~km})$ to 50 miles $(80.5 \mathrm{~km})$ (median
\end{abstract}

\footnotetext{
Department of Paediatrics, University College Hospital and Medical School, London WC1

A M BLAKE, RSCN, nursing officer

N MCINTOSH, MRCP, senior registrar

E O R REYNOLDS, FRCP, consultant paediatrician

Department of Medical Physics, University College Hospital Medical School, London WC1

D ST ANDREW, MIERE, electronics engineer
}

eight miles $(12.9 \mathrm{~km})$ ) away. The mean birth weight of the infants was $1702 \mathrm{~g}$ (range 520-4040 g) and their mean gestational age was 32 weeks (range 24-42 weeks). The principal reasons for referral were low birth weight and severe respiratory illnesses. Altogether $109(49 \%)$ of the infants needed mechanical ventilation in transit and another $38(17 \%)$ needed it later. During the journey the condition of $88(40 \%)$ of the infants was thought to improve, in $125(56 \%)$ it was static and in nine $\left(4^{\%} \%\right)$ four of whom died-it deteriorated. A total of 142 infants $\left(64^{\circ}{ }_{0}\right)$ survived the neonatal period. There was no correlation between the distance travelled and the survival rate.

Seriously ill newborn infants may be transported safely to a referral centre within a radius of $\mathbf{5 0}$ miles, and the risks of the journey are negligible compared with the risks of leaving the infant in a hospital that is not staffed or equipped for neonatal intensive care.

\section{Introduction}

The successful management of infants of low birth weight or those who are seriously ill requires techniques similar to those 